\title{
The Impact of Parents' Educational Level and Students' Gender on Students' Science Academic Achievement in Four Southeast Asian Countries
}

\author{
Quang-Vinh Trinh ${ }^{1}$ \\ ${ }^{1}$ Nguyen Tat Thanh University, Vietnam
}

\begin{tabular}{l}
\hline \hline Article Info \\
\hline Article history: \\
Received Jun 28, 2020 \\
Revised Ags 3, 2020 \\
Accepted Sep 28, 2020 \\
\hline
\end{tabular}

Keywords:

Gender

Science academic achievement Southeast Asia countries Parents' educational level PISA

\begin{abstract}
ABSTRAK
Purpose of study: This paper aims at exploring the factors that affect the science academic achievement of Indonesia, Singapore, Thailand, and Vietnam students by using the PISA 2015 dataset.
\end{abstract}

Methodology: This paper uses a data mining method to explore the PISA 2015 data to answer the research questions and achieve the research aims. The targeted students were selected from ASEAN countries, including Indonesia, Singapore, Thailand, and Vietnam. The total number of samples was 26,703 students and their age ranged from 15.3 to 16.2.

Main finding: The results of this paper indicate parents' educational level and students' gender create significant differences in students' science academic achievement in four Southeast Asian countries.

Novelty/Originality of this study: The paper intends to explore significant differences in the students' science academic achievement, between parents' educational level and students' gender in four Southeast Asian countries.

Copyright @ 2020 Cahaya Ilmu Cendekia Publisher. All rights reserved.

\section{Corresponding Author:}

Quang-Vinh Trinh

Nguyen Tat Thanh University, Vietnam

Email: tqvinh2009@gmail.com

\section{INTRODUCTION}

Opportunity, equity, and equality in education are very important for education policy. So many countries are interested in achieving equity and equality through a set of educational policies to improve people's knowledge, train human resources, and develop socio-economy. However, the impact of parents' educational level and students' gender constitute the significant differences in students' academic achievement in Southeast Asian countries [1].

Parents' educational level plays a higher positive effect on the students. The relevance of parents' educational level on the students' academic achievement is also in line with other literature results [2-9]. Jabor et al (2011) argue that parents' educational level is considered one of the most stable aspects of socioeconomic status because it is typically established at an early age and tends to remain the same over time [10]. Kalender and Berberoglu (2009) propose that parents' educational level may represent the most important variable related to science academic achievement [5]. Caldas and Bankston (1997) also used parents' educational level and occupational background as a measure of family social status to investigate the relationship between social status and science academic achievement [11]. Their results indicated that family social status, in particular, does have a significant and substantive independent effect on individual science performance. The analysis of Kleinjans (2010) on the effect of parents' educational level and income on the educational expectations of children at age 19 [6].

Mohammadpour (2013) used the TIMSS 2007 results to show that the female eighth-grade students had significantly better science academic achievement than their male counterparts [12]. Concerning the 
relationships among the variables affecting science academic achievement, Akpinar et al. (2009) analyzed 658 students to demonstrate that there were significant differences between female and male students regarding "interest in science," akin to students' attitudes in this study, with females demonstrating greater interest [13]. Besides, Velayutham et al. (2012) used multi-group analysis to examine gender differences and revealed that the influence of task value on self-regulation in science academic achievement was only statistically significant for boys [14]. Moreover, Hong and Lin (2011) indicated that there was a significantly greater percentage of Taiwanese boys with high and medium self-confidence in learning science than girls [15]. They also reported that the girls in their study had significantly lower scores than boys.

The Organization for Economic Co-operation and Development's (OECD) PISA also focuses on using mathematics. It is designed to assess the readiness of 15-year-olds for life beyond school, focusing on the extent to which students can use their knowledge and skills to meet real-life challenges. This reflects a change in curricular goals and objectives in many countries, which are increasingly concerned with what students can do with what they learn at school [16]. Programme for International Student Assessment (PISA) is a 3-year cycle of international assessments organised by the Organisation for Economic Co-operation and Development (OECD) since 2000. In each cycle, PISA has assessed three key fields of knowledge and skill, namely reading, mathematics, and science literacies [17]. PISA offers insight for education policy and practice, which helps to monitor trends in students' acquisition of knowledge, and skills across countries, economies, and different demographic subgroups within each country. More specifically, PISA provides reliable empirical evidence to identify the strengths and weaknesses of the education systems. PISA 2015 focused on measuring student science literacy and its data collection covered 72 countries [18].

The scientific literacy assessment in PISA interests in assessing to what extent students explain phenomena scientifically, evaluate, and design scientific surveys, interpret data and evidence scientifically. The process of scientific literacy assessment is particularly important in PISA study because the acquisition of scientific and technological knowledge in society is an indicator of the ability of individuals to participate actively in it, so this kind of knowledge has become a priority for the countries that wish to prepare their societies for life, and in improving their standard of living.

Because the measurement of PISA is quite comprehensive and credible, this paper used this database of PISA to select the targeted samples. In addressing the paper gap, the purpose of this paper is to analyze parents' educational level and students' gender influence students' science academic achievement in four Southeast Asian countries. Three research questions were designed in agreement with the aims of this paper.

1) How is the students' science academic achievement in four Southeast Asian countries?

2) Are there significant differences in the science academic achievement and gender in four Southeast Asian countries' students?

3) Are there significant differences in students' science academic achievement, between parents' educational level and students' gender in four Southeast Asian countries?

\section{RESEARCH METHOD}

This paper uses a data mining method to explore the PISA 2015 data to answer the research questions and achieve the research aims. The targeted students were selected from ASEAN countries, including Indonesia, Singapore, Thailand, and Vietnam. The total number of samples was 26,703 students and their age ranged from 15.3 to 16.2 (see Table 1)

Table 1. Sample sizes of Indonesia, Singapore, Thailand, and Vietnam

\begin{tabular}{ccccc}
\hline $\begin{array}{c}\text { Ceuntry } \\
\text { Gendex }\end{array}$ & Indonesia & Singapore & Thailand & Vietnam \\
\hline Female & 3,343 & 2,973 & 4,652 & 3,040 \\
Male & 3,170 & 3,142 & 3,597 & 2,786 \\
Total & 6,513 & 6,115 & 8,249 & 5,826 \\
\hline
\end{tabular}

The selected variables in this paper are country (Indonesia, Singapore, Thailand, and Vietnam), parents' educational level (seven groups (0), (1), (2), (3), (4), (5), and (6)), students' gender (Female and Male), and science academic achievement (PViSCIE, $\mathrm{i}=1,2, \ldots, 10)$. The definitions of the research variables are as follows: Country (CNT): is coded 3-character consisting of Indonesia (IDN), Singapore (SGF), Thailand (THA), and Vietnam (VNM).

Parents' educational level (ISCED): This index is constructed by taking the highest level of father and mother and having the following categories: (0) None (not received training), (1) Completed ISCED level 1 (primary education), (2) Completed ISCED level 2 (lower secondary education), (3) Completed 
ISCED levels 3B or 3C (upper secondary education providing direct access to the labor market or to ISCED 5B programs), (4) Completed ISCED level 3A (upper secondary education providing access to ISCED 5A and 5B programs) and/or ISCED level 4 (non-tertiary post-secondary), (5) Completed ISCED level 5B (nonuniversity tertiary education), (6) Completed ISCED level 5A (university level tertiary education) or ISCED level 6 (advanced research programs) (OECD, $1999 \& 2016$ ) (see Table 2).

Table 2. Mapping of International Standard Classification of Education (ISCED) to years

\begin{tabular}{ccccccc}
\hline Country & \multirow{2}{*}{ ISCED 1 } & \multirow{2}{*}{ ISCED 2 } & $\begin{array}{c}\text { ISCED 3B, } \\
\text { 3C }\end{array}$ & $\begin{array}{c}\text { ISCED 3A/ } \\
\text { ISCED 4 }\end{array}$ & $\begin{array}{c}\text { ISCED 5B } \\
\text { ISCED 5A/ } \\
\text { ISCED 6 }\end{array}$ \\
\hline Indonesia & 6 & 9 & 12 & 12 & 14 & 15 \\
Singapore & 6 & 8 & 10 & 11 & 13 & 16 \\
Thailand & 6 & 9 & 12 & 12 & 14 & 16 \\
Vietnam & 5 & 9 & 12 & 12 & - & 17 \\
\hline
\end{tabular}

(Source: OECD, 2016)

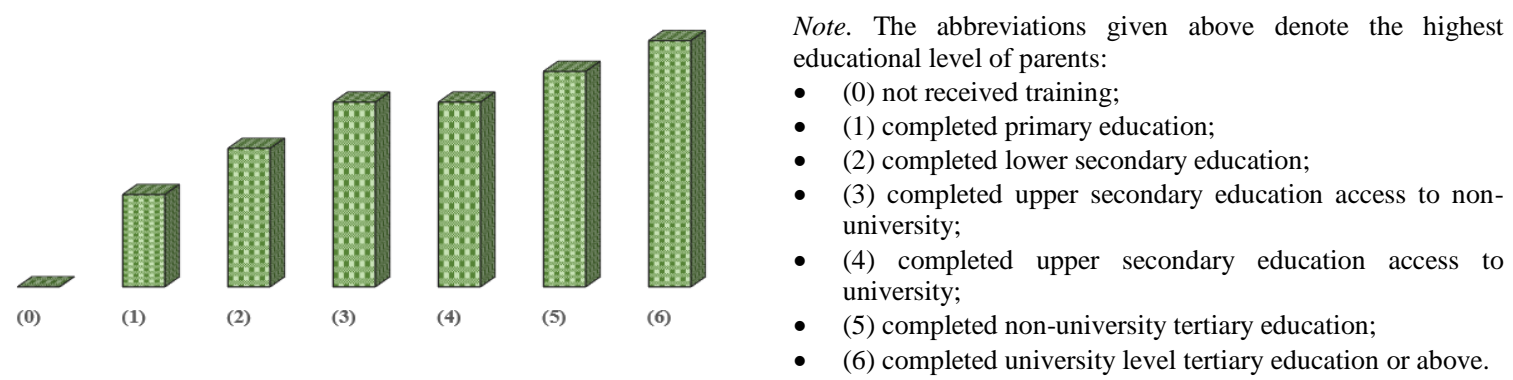

Figure 2. This index of parents' educational level.

Students' gender (GENDER): Based on students' answers to the question on gender (female=1, male=0). Science academic achievement $(P V i S C I E)$ : This used ten multi-dimensional scaling models respective ten plausible values from PV1SCIE to PV10SCIE [18].

Data analysis was performed with IBM - SPSS 23.0 software. Descriptive analysis was used to answer the research question 1: "How is the students' science academic achievement in four Southeast Asian countries?". Independent-Sample t-Test analysis was used to answer the research question 2: "Are there significant differences in the science academic achievement and gender in four Southeast Asian countries' students?". One-Way ANOVA analysis was used to answer the research question 3: "Are there significant differences in the students' science academic achievement, between parents' educational level and students' gender in four Southeast Asian countries?".

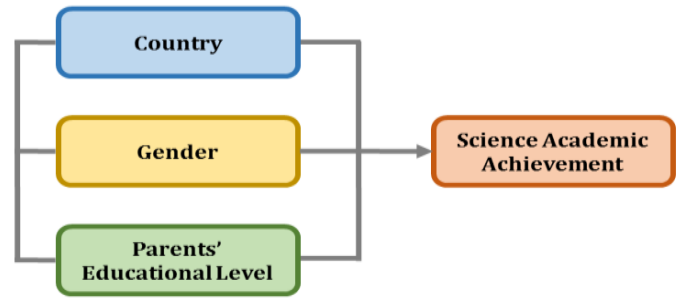

Figure 1. Research framework

\section{RESULTS AND DISCUSSION}

The paper intends to explore significant differences in the students' science academic achievement, between parents' educational level and students' gender in four Southeast Asian countries.

\subsection{The students' science academic achievement in four Southeast Asian countries}

The overall statistics of the students' science academic achievement in four Southeast Asian countries. It indicates that the students' Science Academic Achievement is not high in Indonesia $(\mathrm{M}=408-$ 411, $\mathrm{Me}=404-407, \mathrm{SD}=68-70)$, and in Thailand $(\mathrm{M}=433-434, \mathrm{Me}=425-426, \mathrm{SD}=87-89)$, whereas the indicators are very high in Singapore $(\mathrm{M}=546-547, \mathrm{Me}=553-555, \mathrm{SD}=104-105)$, and high in Vietnam $(\mathrm{M}=525-527, \mathrm{Me}=522-524, \mathrm{SD}=75-76)$. The students' science academic 
achievement in all four Southeast Asian countries is calculated with $\mathrm{M}=473-474, \mathrm{Me}=466-467$, and SD $=103$.

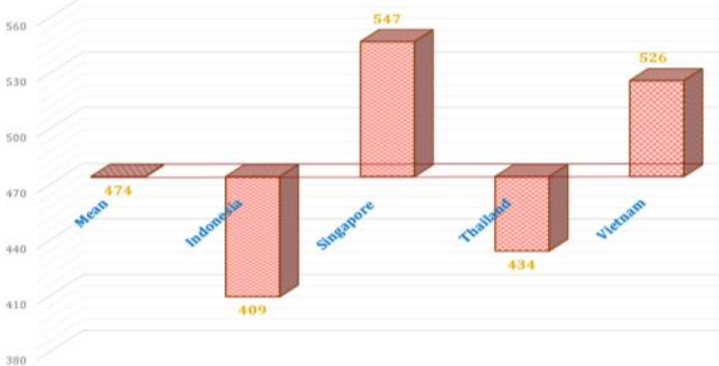

Figure 3. The students' science academic achievement in four Southeast Asian countries

As shown in Figure 3, the mean of students' science academic achievement in all four Southeast Asian countries is 474 points. Specifically, the highest number among the four countries can be found in Singapore with 547 points, followed by Vietnam with 526 points, Thailand with 434 points, while Indonesia obtained the lowest science academic achievement of 409 points.

Overall, the coefficient of Skewness in Thailand $(0.31-0.34)$ shows the highest level, followed by Indonesia $(0.20-0.27)$ and Vietnam $(0.17-0.26)$, which means the distribution of the students' science academic achievement skewed to the left. Singapore $(-0.25--0.19)$ skewed to the right. The coefficients of Kurtosis in Thailand $(-0.38--0.32)$ and Singapore $(-0.33--0.29)$, have the distribution of the students' science academic achievement lower than the peakedness. Vietnam and Indonesia were the most stable country, less affected by the coefficient of Kurtosis (see Figure 4).

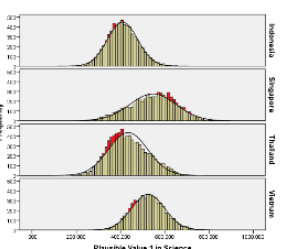

(a)

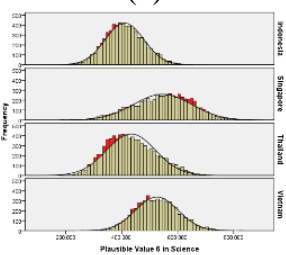

(f)

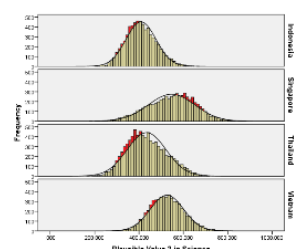

(b)

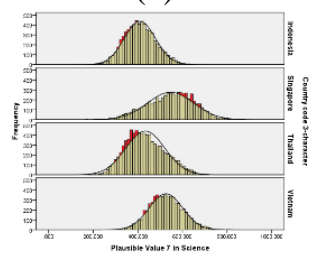

(g)

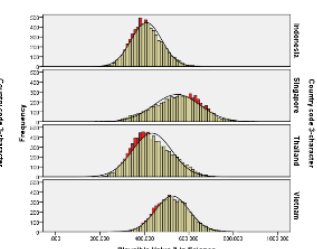

(c)

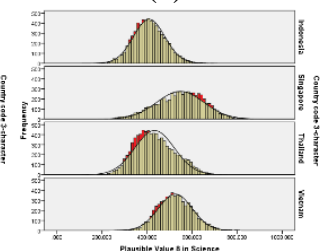

(h)

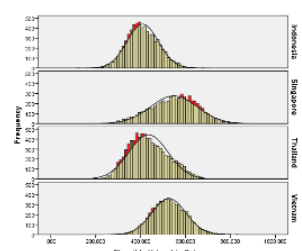

(d)

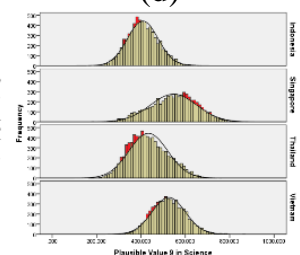

(i)

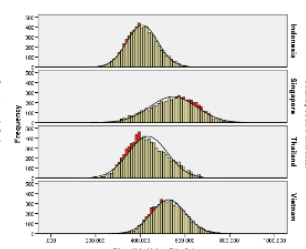

(e)

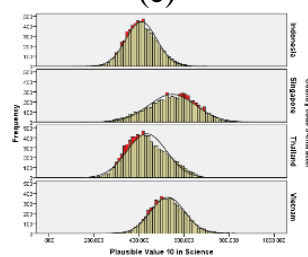

(j)

Figure 4. The distribution of the science academic achievement in four Southeast Asian countries' students

\subsection{The differences of the science academic achievement and gender in four Southeast Asian countries' students}

Regarding the relationship between female and male students on science academic achievement, there were significant differences between female and male students on science academic achievement.

In Indonesia, six science academic achievement values are PV1SCIE, PV2SCIE, PV4SCIE, PV6SCIE, PV7SCIE, and PV10SCIE ( $\mathrm{t}$ from 2.02 to $2.39, \mathrm{p}<0.05$ ) and four science academic achievement values are PV3SCIE, PV5SCIE, PV8SCIE, and PV9SCIE ( $\mathrm{t}$ from 2.71 to $3.08, \mathrm{p}<0.01$ ). The finding of post-hoc comparison shows that the science academic achievement of female students $(\mathrm{M}=411, \mathrm{SD}=69)$ was better than male students $(M=407, S D=69)$.

In Thailand, all science academic achievement values from PV1SCIE to PV10SCIE have (t from 3.46 to 4.83 , $p<0.001)$. The finding of post-hoc comparison shows that the science academic achievement of female students $(M=438, S D=86)$ was also better than male students $(M=429, S D=90)$.

Especially for the case of Singapore and Vietnam (ten science academic achievement values from PV1SCIE to PV10SCIE have $\mathrm{p}>.05$ ), it is impossible to conclude that there were statistically significant differences in the students' science academic achievement between female and male. So to determine 
whether there are statistically significant differences in the science academic achievement between female and male in these two countries, further analysis will be conducted at the bottom.

\subsection{The differences of the students' science academic achievement, between parents' educational level and students' gender in four Southeast Asian countries}

Regarding the relationship between female and male students among seven groups of parents' educational level on the science academic achievement, there were significant differences between female and male students among parents' educational level groups on the science academic achievement.

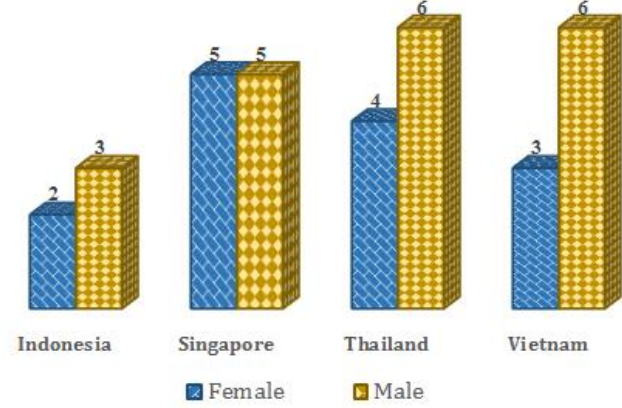

Figure 5. The differences of gender and parents' educational level on the students' science academic achievement in four Southeast Asian countries.

In Indonesia, all science academic achievement values from PV1SCIE to PV10SCIE have (p < 0.001). Furthermore, the finding post-hoc comparison shows that the science academic achievement of female students in the group (2) or more were better than the group (0) and (1). In contrast, its male students in the group (3) or more was better than the group (0), (1), and group (2).

In Singapore, all science academic achievement values from PV1SCIE to PV10SCIE have ( $\mathrm{p}<$ 0.001). Furthermore, the finding post-hoc comparison shows that the science academic achievement of female and male students in the group (5) and (6) was better than the remaining groups. Besides, the science academic achievement of female students in six groups (0), (1), (2), (4), (5), and (6) was lower than male students.

In Thailand, all science academic achievement values from PV1SCIE to PV10SCIE have ( $\mathrm{p}<$ 0.001). Furthermore, the finding post-hoc comparison shows that the science academic achievement of female students in the group (4) and (6) was better than the remaining groups. Moreover, its male students in a single group (6) was better than the remaining groups.

In Vietnam, all science academic achievement values from PV1SCIE to PV10SCIE have ( $\mathrm{p}<$ 0.001). Furthermore, the finding post-hoc comparison shows that the science academic achievement of female students in the group (3) or more was better than the group (0), (1), and group (2). Moreover, its male students in a single group (6) was better than the remaining groups. Also, the science academic achievement of female students in three groups (3), (4), and (6) was better than male students.

\section{CONCLUSION}

The important findings of this paper were parents' educational level and students' gender create significant differences in students' science academic achievement in four Southeast Asian countries, as follows:

Initially, this study has shown that Singapore (547 points) has the highest academic achievement in science and Vietnam (526 points), above the average of Southeast Asian countries in science (474 points), followed by Thailand (434 points), and Indonesia (409 points) has the lowest academic achievement in science.

Secondly, the finding of this study indicated that the science academic achievement of female students was better than male students in Indonesia, Thailand, and Vietnam, but the science academic achievement of female students was lower than male students in Singapore. There are similarities between the attitudes expressed by the students' gender in this study and those described by Mohammadpour (2013), Akpinar et al. (2009), Velayutham et al. (2012), Hong and Lin (2011), and Ababneh and Abdel (2018), [12, $13,14,15,19]$. In Indonesia and Thailand, diligence and self-efficacy may contribute significantly towards explaining variation in science academic achievement. Therefore, we will give more evidence in the subsequent studies. 
Finally, the finding of independent t-test and one-way ANOVA found that regarding the relationship between parents' educational level and students' gender factors on the students' science academic achievement in four Southeast Asian countries. The female reaches better academic achievement in science when their parents have completed lower secondary education or higher level, similar to the male when their parents have completed upper secondary education or higher level in Indonesia. Both female and male, whose parents have a non-university level tertiary educations or higher level, are better than other students in Singapore. In Thailand and Vietnam: Parents, whose females are good at science than other females, have ended upper secondary education or higher level; Also, males, whose parents just have graduated university level tertiary education or above, are good at science than other males. The result of this finding has been well described in previous studies [12-15, 20-24]. These findings of the current study are consistent with those of Trinh and Weng (2017) who found parents' educational level and students' gender create the significant differences of students' academic achievement in four Southeast Asian countries.

\section{ACKNOWLADGEMENT} very much.

Thank you to all colleagues who have helped me and all parties involved in this research, thank you

\section{REFERENCE}

[1] Trinh, Q. V., \& Weng, F., Y. "The impact of factors on mathematics performance of Vietnamese and Southeast Asian countries' students - A comparative perspective". Taiwan Education Review Journal, vol. 6, no. 11, pp. 66 84, 2017.

[2] Brunello, G., \& Checchi, D. "School quality and family background in Italy". Economics of Education Review, vol. 24, no. 5, pp. $563-577,2005$.

[3] Cameron, S. V., \& Heckman, J. "The dynamics of educational attainment for black, hispanic, and white males". Journal of Political Economy, vol. 109, no. 3, pp. 455 - 499, 2001.

[4] Chang, C. Y., \& Cheng, W. Y. "Science achievement and students' self-confidence and interest in science: A Taiwanese representative sample study”. International Journal of Science Education, vol. 30, no. 9, pp. 1183 - 1200 , 2008.

[5] Kalender, I., \& Berberoglu, G. "An assessment of factors related to science achievement of Turkish students". International Journal of Science Education, vol. 31, no. 10, pp. 1379 - 1394, 2009.

[6] Kleinjans, K. J. "Family background and gender differences in educational expectations". Economics Letters, vol. 107, no. 2, pp. $125-127,2010$.

[7] Senler, B., \& Sungur, S. "Parental influence on students' self-concept, task value beliefs, and achievement in science". The Spanish Journal of Psychology, vol. 12, no. 1, pp. 106 -117, 2009.

[8] Sullivan, A. "Cultural capital and educational attainment. Sociology", vol. 35, no. 4, pp. 893 - 912, 2001.

[9] Thomson, S. "Examining the evidence from TIMSS: Gender differences in year 8 science achievement in Australia". Studies in Educational Evaluation, vol. 34, pp. 73 - 81, 2008.

[10] Jabor, M. K., Machtmes, K., Kungu, K., Buntat, Y., \& Nordin, M. S. "Does parent educational status matter on the students' achievement in science?" Paper presented in the 2011 International Conference on Social Science and Humanity, Singapore.

[11] Caldas, S. J., \& Bankston, C. L. "The effect of school population socioeconomic status on individual student academic achievement”. Journal of Educational Research, vol. 90, pp. 269 - 277, 1997.

[12] Mohammadpour, E. "A three-level multilevel analysis of Singaporean eighth-graders science achievement". Learning and Individual Differences, vol. 26, pp. 212 - 220, 2013.

[13] Akpinar, E., Yildiz, E., Tatar, N., \& Ergin, O. "Students' attitudes toward science and technology: An investigation of gender, grade level, and academic achievement”. In H. Uzunboylu, \& N. Cavus (Eds.), World conference on educational sciences-New trend sand issues in educational sciences, 1, pp. $2804-2808$. Amsterdam, Netherlands: Elsevier Science Bv., 2009.

[14] Velayutham, S., Aldridge, J., \& Fraser, B. "Gender differences in student motivation and self-regulation in science learning: A multi-group structural equation modeling analysis". International Journal of Science and Mathematics Education, vol. 10, no. 6, pp. $1347-1368,2012$

[15] Hong, Z. R., \& Lin, H. S. "An investigation of the students' personality traits and attitudes toward science". International Journal of Science Education, vol. 33, no. 7, pp. 1001 - 1028, 2011.

[16] OECD. "The PISA 2003 assessment framework: Mathematics, reading, science and problem solving knowledge and skills", 2003. Retrieved from https://www.oecd.org/edu/school/programmeforinternationalstudent assessment pisa/35188570.pdf 
[17] OECD. "PISA 2012 Results: What Students Know and Can Do - Student Performance in Mathematics, Reading and Science (Volume I)", 2013. Retrieved from https://www.oecd.org/pisa/keyfindings/pisa-2012-results-volume-I.pdf

[18] OECD. "PISA 2015 Results in Focus". Paris: OECD Publications, 2016.

[19] Ababneh, E. G., \& Abdel Samad, M. M. "Gender gap in science achievement for Jordanian students in PISA2015". European Journal of Educational Research, vol. 7, no. 4, pp. 963-972, 2018. doi: 10.12973/eu-jer.7.4.963

[20] Chiu, M. S. "Effects of a women-in-sciences/men-inhumanities intervention on Taiwanese adolescents' attitudes towards learning science". The Asia - Pacific Education Researcher, vol. 20, no. 2, pp. 322 - 335, 2011.

[21] Liu, O. L., Lee, H. S., \& Linn, M. C. "An investigation of teacher impact on student inquiry science performance using a hierarchical linear model”. Journal of Research in Science Teaching, vol. 47, no. 7, pp. 807 - 819, 2010.

[22] Pomerantz, E. M., Altermatt, E. R., \& Saxon, J. L. "Making the grade but feeling distressed: Gender differences in academic performance and internal distress". Journal of Educational Psychology, vol. 94, pp. 396 - 404, 2002.

[23] Tindara, A., Maria, L. D. T., \& Anna, M. "Education capability: A focus on gender and science". Social Indicators Research, vol. 128, no. 2, pp. $793-812,2016$.

[24] Tsai, L. T., Yang, C. C., \& Chang, Y. J. "Gender differences in factors affecting science performance of eighth grade Taiwan students". The Asia - Pacific Education Researcher, vol. 24, no. 2, pp. 445 - 456, 2015. 